\title{
Haemostatic factors associated with ischaemic heart disease in men aged 45 to 64 years The Speedwell study
}

\author{
I A BAKER,^ R EASTHAM, P C ELWOOD, M ETHERINGTON, J R O’BRIEN, \\ P M SWEETNAM
}

From the MRC Epidemiology Unit, Cardiff; Frenchay Hospital, Bristol; and St Mary's General Hospital, Portsmouth

SUMMARY In the Speedwell study set up to examine primarily the relation of plasma lipids and ischaemic heart disease in men aged 45 to 64 years drawn randomly from the practices of 16 general practitioners, various haemostatic factors which may contribute both to thrombogenesis and atherogenesis were measured. Fibrinogen measured nephelometrically and plasma viscosity were positively associated with the prevalence of ischaemic heart disease. Antithrombin III was negatively associated with the prevalence of ischaemic heart disease. These associations were statistically significant at the $1 \%$ level of probability. Fibrinogen measured by a clotting method and the heparin neutralising activity of platelet poor plasma had negative and positive associations with ischaemic heart disease, respectively, but neither association achieved statistical significance. Because of the interrelation of these variables and also age, a multiple logistic regression analysis was undertaken separately for the two measures of fibrinogen. The negative association of "clottable" fibrinogen and the positive association of plasma viscosity with the prevalence of ischaemic heart disease were confirmed and both were statistically significant at the $5 \%$ level of probability. Apart from age the independent association of the other variables with ischaemic heart disease did not achieve statistical significance. Fibrinogen measured by both methods had positive and statistically significant associations with serum total cholesterol, but no associations with serum total triglycerides, smoking, or alcohol consumption. "Clottable" fibrinogen had an inverse and statistically insignificant association with serum high density lipoprotein cholesterol. The observed associations support the concept of the involvement of some haemostatic factors in the aetiology of ischaemic heart disease, and these associations are now being examined more critically in a longitudinal study.

In considering the aetiology of ischaemic heart disease it is necessary to study the elements of thrombogenesis as well as atherogenesis. Patients dying from myocardial infarction show evidence of coronary artery thrombosis, which antedates the infarction, as well as atheroma. ${ }^{12}$ Other evidence indicates that substances in the blood which are thrombogenic may also be involved in the process of atherogenesis and arterial occlusion and thereby other clinical manifestations of ischaemic heart disease. Fibrin and platelets are present in mural thrombi and atherosclerotic plaques. $^{3-6}$ In developing plaques in the human aorta, Smith et al. ${ }^{7}$ found increased concentrations of free ^Present address: Avon Area Health Authority, Greyfriars, Lewin's Mead, Bristol BS1 2EE.

Accepted for publication 5 January 1982 low density lipoprotein and fibrinogen and in more advanced plaques high concentrations of the same lipoprotein bound to fibrin. Platelets may also aggregate and embolise causing myocardial damage and irritability ${ }^{8}$; or by the release of active substances alter arterial ton $\mathrm{e}^{10}$; or contribute to atheroma formation. ${ }^{11}$ At the same time, a number of elements exist, like antithrombin III, which can neutralise activated clotting factors and which may influence the extent of the above thrombotic and atherogenic processes. Finally, fibrinogen is also important in determining plasma viscosity and thereby influencing blood flow through occluding arteries.

Within the design of the Speedwell study 12 which is to examine longitudinally the relation between serum lipoproteins and ischaemic heart disease the feasibility 
of measuring some of these haemostatic factors was considered. Selection of the factors measured was influenced by the need to collect large numbers of blood specimens at a distance from laboratories as well as intra- and inter-subject variability of the individual factors. The results of the pilot study and the associations between the factors measured and prevalent ischaemic heart disease and other risk indications for ischaemic heart disease are reported.

\section{Patients and methods}

The design of the study has been described in the paper giving results of lipid and related measurements and ischaemic heart disease in the same population. ${ }^{12}$ Venous blood samples were collected from men aged 45 to 64 years who were in a fasting state in the early morning. For subjects reporting minor illness, or major illness or surgery, blood samples were collected, respectively, two weeks or three months later. Fibrinogen was estimated by two different methods. "Clottable" fibrinogen $(C)$ was measured in citrated plasma by the method of Clauss. ${ }^{13}$ In the second method using EDTA plasma, fibrinogen (N) was measured by a heat precipitation nephelometric method. ${ }^{14}$ Plasma viscosity was measured within a few hours of blood collection in the EDTA specimen using the method of Harkness. ${ }^{15}$ Platelet count and haematocrit were determined by the Coulter $S$ counter. Antithrombin III was measured biologically in serum by the method of von Kaulla ${ }^{16}$ and immunologically by single radial immunodiffusion according to the method of Mancini et al. ${ }^{17}$ The heparin neutralising activity of platelet poor plasma was measured using the heparin thrombin clotting time test. ${ }^{18}$ The plasma response to thrombin was also monitored by a dilute thrombin clotting time test. ${ }^{18}$ Estimations of platelet aggregation response to dilutions of adenosine diphosphate were carried out turbidometrically on citrated platelet rich plasma within two hours of collection. Within the four dilutions of adenosine diphosphate used we were unable to obtain consistent patterns of aggregation with which to quantify the responses of subjects and relate them to the prevalence of ischaemic heart disease. These estimations were discarded. Determination of the prevalence of ischaemic heart disease and other "risk factors" has been described in the paper giving results for the lipid analysis.

\section{Results}

Reproducibility of measurements was estimated from split specimens of blood taken from a subsample of subjects. Expressed as coefficients of variation, the estimations of reproducibility are shown in Table 1.
Table 1 Reproducibility-duplicate pair analysis

\begin{tabular}{|c|c|c|c|}
\hline Test & $\begin{array}{l}\text { No. of } \\
\text { pairs }\end{array}$ & $\begin{array}{l}\text { Overall } \\
\text { mean }\end{array}$ & $\begin{array}{l}\text { Coefficient } \\
\text { of variation (\%) }\end{array}$ \\
\hline \multicolumn{4}{|l|}{ Fibrinogen } \\
\hline Clottable $(\mathrm{g} / \mathrm{l})$ & 46 & $2 \cdot 97$ & $7 \cdot 5$ \\
\hline Nephelometric $(\mathrm{g} / \mathrm{l})$ & 46 & $4 \cdot 20$ & 6.0 \\
\hline Viscosity (centipoises) & 47 & 1.65 & 1.8 \\
\hline Thrombin clotting time (s) & 46 & $17 \cdot 4$ & $6 \cdot 1$ \\
\hline \multicolumn{4}{|l|}{ Heparin thrombin clotting } \\
\hline time (s) & 46 & $31 \cdot 1$ & $14 \cdot 1$ \\
\hline \multicolumn{4}{|l|}{ Antithrombin III } \\
\hline Biological (s) & 44 & $37 \cdot 5$ & $27 \cdot 8$ \\
\hline Immunological ( $\mathrm{g} / \mathrm{l})$ & 44 & $0 \cdot 22$ & $11 \cdot 6$ \\
\hline $\begin{array}{l}\text { Platelet count }\left(10^{9} / 1\right) \\
\text { Haematocrit }(\%)\end{array}$ & $\begin{array}{l}47 \\
47\end{array}$ & $\begin{array}{l}184000 \\
0.45\end{array}$ & $\begin{array}{l}8 \cdot 2 \\
2 \cdot 5\end{array}$ \\
\hline
\end{tabular}

Reproducibility of all measurements was acceptable except for the "biological assay" of antithrombin III by the von Kaulla method.

Mean values for the various factors measured for the population divided into those with "any" evidence of ischaemic heart disease by history and electrocardiogram and those without any such evidence are shown in Table 2. The variables for which the difference between those with and without ischaemic heart disease reached statistical significance were fibrinogen (N), plasma viscosity, and antithrombin III by immunological assay. While fibrinogen $(\mathrm{N})$ levels were higher in men with ischaemic heart disease, fibrinogen $(C)$ was higher in men without ischaemic heart disease. Antithrombin III activity estimated by the von Kaulla test gave differences for men with and without ischaemic heart disease in the same direction as that measured immunologically, but the differences were not statistically significant. The thrombin clotting times were similar in men with and without evidence of ischaemic heart disease. The heparin thrombin clotting times were shorter in men with ischaemic heart disease, indicating increased heparin neutralising activity (Table 3 ).

Interrelations existed between age, fibrinogen measured by both methods, heparin thrombin clotting times, viscosity, and antithrombin III as shown in the correlation matrix in Table 4. As fibrinogen has heparin neutralising activity and contributes significantly to plasma viscosity, a multiple logistic regression analysis was performed to see which if any of these variates (excluding antithrombin III) were independently associated with ischaemic heart disease. The regression was performed twice-one model included fibrinogen $(\mathrm{N})$ and the second model included fibrinogen $(\mathrm{C})$. Table 5 shows the regression coefficients for both models expressed in standard units. These units show the change in the logit of risk for one standard deviation change in the variable and allow for easier comparison of the relative importance of the independent variables. Age was an important predictor of ischaemic heart disease in both models and its positive associations were statistically 
Table 2 Association of ischaemic heart disease with haematological variables

\begin{tabular}{|c|c|c|c|c|}
\hline \multirow[t]{2}{*}{ Variable } & \multicolumn{2}{|c|}{ No ischaemic heart disease } & \multicolumn{2}{|c|}{ Any ischaemic heart disease } \\
\hline & No. of subjects & Mean (SD) & No. of subjects & Mean $(S D)$ \\
\hline $\begin{array}{l}\text { Fibrinogen } \\
\text { Clottable }(g / \mathbf{l}) \\
\text { Nephelometric }(g / \mathbf{l}) \\
\text { Viscosity (centipoises) } \\
\text { Platelet count }\left(10^{9} / \mathbf{l}\right) \\
\text { Haematocrit } \\
\text { Antithrombin III }\end{array}$ & $\begin{array}{l}226 \\
223 \\
223 \\
221 \\
225\end{array}$ & $\begin{array}{cc}2.97 & (0.63) \\
4.02 & (0.93) \\
1.64 & (0.09) \\
184 & (54) \\
0.455 & (0.03)\end{array}$ & $\begin{array}{l}55 \\
53 \\
53 \\
52 \\
54\end{array}$ & $\begin{array}{cl}2.87 & (0.61) \\
4.39 & (0.85)^{\star} \\
1.69 & (0.10)^{\star} \\
188 & (51) \\
0.448 & (0.04)\end{array}$ \\
\hline $\begin{array}{l}\text { Biological (s) } \\
\text { Immunological (g/l) }\end{array}$ & $\begin{array}{l}217 \\
217\end{array}$ & $\begin{array}{cc}37.3 & (17.1) \\
0.23 & (0.03)\end{array}$ & $\begin{array}{l}52 \\
54\end{array}$ & $\begin{array}{cl}34.8 & (16.8) \\
0.21 & (0.03)^{\star}\end{array}$ \\
\hline \multicolumn{5}{|l|}{${ }^{\star} p<0.01$} \\
\hline \multirow[t]{2}{*}{ Variable } & \multicolumn{2}{|c|}{ No ischaemic heart disease } & \multicolumn{2}{|c|}{ Any ischaemic heart disease } \\
\hline & No. of subjects & Mean $(S D)$ & No. of subjects & Mean $(S D)$ \\
\hline \multirow{2}{*}{$\begin{array}{l}\text { Thrombin clotting test time (s) } \\
\text { Heparin thrombin } \\
\text { clotting test time (s) }\end{array}$} & 223 & $17 \cdot 4 \quad(1 \cdot 2)$ & 54 & $17 \cdot 6 \quad(1 \cdot 2)$ \\
\hline & 223 & $32 \cdot 2(10 \cdot 0)$ & 54 & $30.0 \quad(8.8)$ \\
\hline
\end{tabular}

Table 4 Haematological variables-correlation matrix

\begin{tabular}{|c|c|c|c|c|c|c|}
\hline & Age & Fibrinogen $(N)$ & Fibrinogen $(C)$ & Viscosity & $\begin{array}{l}\text { Heparin } \\
\text { thrombin } \\
\text { clotting time }\end{array}$ & Antithrombin $I I I(i)$ \\
\hline $\begin{array}{l}\text { Age } \\
\text { Fibrinogen (N) } \\
\text { Fibrinogen (C) } \\
\text { Viscosity } \\
\text { Heparin thrombin } \\
\text { clotting time } \\
\text { Antithrombin III (i) }\end{array}$ & $\begin{array}{l}1 \\
0 \cdot 24^{\star \star \star} \\
0 \cdot 09 \\
0 \cdot 20^{\star \star} \\
-0 \cdot 12^{\star} \\
-0 \cdot 19^{\star \star}\end{array}$ & $\begin{array}{l}1 \\
0 \cdot 40^{\star \star \star} \\
0 \cdot 60^{\star \star \star} \\
-0 \cdot 40^{\star \star \star} \\
-0 \cdot 14^{\star}\end{array}$ & $\begin{array}{l}1 \\
0.35^{\star \star \star} \\
-0.46^{\star \star \star} \\
0.14^{\star}\end{array}$ & $\begin{array}{l}1 \\
-0 \cdot 35^{\star \star \star} \\
-0 \cdot 13^{\star}\end{array}$ & $\begin{array}{l}1 \\
0.09\end{array}$ & 1 \\
\hline
\end{tabular}

Fibrinogen (N), nephelometric; Fibrinogen (C), clottable; Antithrombin III (i), immunological.

No. of subjects varies between 265 and 281 .

${ }^{\star} \mathrm{p}<0.05, \star \star \mathrm{p}<0.01, \star \star \star \mathrm{p}<0.001$.

Table 5 Multiple logistic regression coefficients for two models with different estimations of fibrinogen

\begin{tabular}{|c|c|c|c|}
\hline Variable & $\begin{array}{l}\text { Standardised regression } \\
\text { coefficient }(S E)\end{array}$ & Variable & $\begin{array}{l}\text { Standardised regression } \\
\text { coefficient }(S E)\end{array}$ \\
\hline $\begin{array}{l}\text { Age } \\
\text { Fibrinogen (N) } \\
\text { Viscosity } \\
\text { Heparin thrombin } \\
\text { clotting time }\end{array}$ & $\begin{array}{rr}0.365 & (0.164) \\
0.068 & (0.214) \\
0.336 & (0.198) \\
-0.045 & (0.180)\end{array}$ & $\begin{array}{l}\text { Age } \\
\text { Fibrinogen (C) } \\
\text { Viscosity } \\
\text { Heparin thrombin } \\
\text { clotting time }\end{array}$ & $\begin{array}{rr}0.388 & (0.166) \\
-0.513 & (0.200) \\
0.497 & (0.180) \\
-0.262 & (0.196)\end{array}$ \\
\hline
\end{tabular}

Fibrinogen (N), nephelometric; Fibrinogen (C), clottable.

significant $(p<0.05)$. In the model containing the variate of fibrinogen $(C)$, both fibrinogen and viscosity showed moderate associations in opposite directions with ischaemic heart disease, and both associations were statistically significant $(p<0 \cdot 01)$. A moderate positive association of viscosity with ischaemic heart disease was shown also in the other model, but this association did not reach statistical significance at the $5 \%$ level of probability. The associations of fibrinogen measured by the two methods with ischaemic heart disease independent of the effect of age, viscosity, and heparin thrombin clotting times were in opposite directions. The heparin thrombin clotting times are negatively associated with ischaemic heart disease (that is positive associations for the heparin neutralising activity measured), but the associations in both models are not statistically significant at the $5 \%$ level.

Fibrinogen measured by both methods was positively associated with age (Table 4). Positive but weak associations with serum total cholesterol existed with 
both measures of fibrinogen (fibrinogen $(N) r=0 \cdot 15$, $\mathrm{p}<0.01$; fibrinogen $(\mathrm{C}) \mathrm{r}=0.18, \mathrm{p}<0.01$ ). A negative but statistically insignificant association $(r=-0 \cdot 11)$ existed between serum high density lipoprotein cholesterol and fibrinogen (C). No association was shown with fibrinogen $(\mathrm{N})$ and high density lipoprotein cholesterol, or between either of the two measures of fibrinogen and serum total triglycerides. Fibrinogen $(\mathrm{N})$ had a weak positive association $(\mathrm{r}=0.12, \mathrm{p}<0.05)$ with the obesity index, weightheight $^{2}$. No associations with smoking habit or alcohol consumption were apparent with either measure of fibrinogen.

Plasma viscosity showed positive associations with serum total cholesterol $(r=0.23, p<0.001)$ and serum total triglycerides $(r=0.22, p<0.001)$. No further associations were shown for smoking, alcohol consumption, or obesity index with plasma viscosity, heparin thrombin clotting times, or antithrombin III. Antithrombin III measured immunologically had an inverse association with age (Table 4).

\section{Discussion}

The study was satisfactory in that $86 \%$ of the random samples of men gave fasting blood specimens on which the haemostatic factors were measured. The reproducibility of the measurements, except for the von Kaulla biological assay for antithrombin III, was acceptable. Estimations of platelet aggregation response to dilutions of adenosine diphosphate turbidometrically were inconsistent over the period of the study. Because of the difficulties of interpretation and quantification, this form of assessment of platelet aggregation seems unsuitable for large epidemiological studies.

The two different methods of measuring fibrinogen gave associations with the selected manifestations of ischaemic heart disease. It is not uncommon for measurements of different properties of proteins to have dissimilar associations with other variables. The correlation coefficient of the two measurements of fibrinogen was 0.40 . Hampton et al. ${ }^{19}$ using a chemical estimation of fibrinogen, found higher mean levels and greater variability in levels on repeated samples in subjects with ischaemic heart disease than in subjects of similar age without a history or electrocardiographic evidence of ischaemic heart disease. ${ }^{19}$ Pilgeram ${ }^{20}$ using a method of estimation of fibrinogen which depends on its conversion to fibrin and spectrophotometric quantification of fibrin yield by ninhydrin found fibrinogen levels $20 \%$ higher in patients six months after myocardial infarction than in age matched controls. Meade et al. ${ }^{21}$ have shown positive associations between prevalent ischaemic heart disease and clottable fibrinogen levels in men aged $\mathbf{4 0}$ to 64 and also increased fibrinogen levels in the same population of men who die from cardiovascular disease compared with those who survive over a mean 33 month follow up period. Further studies by Pilgeram $^{22}$ have indicated that raised fibrinogen in patients with coronary thrombosis is associated with an increased rate of biosynthesis and turnover of the molecule. There may also be defects in those patients' capacity to lyse fibrin. ${ }^{22}$

Fibrinogen measured by both methods was associated with age and serum total cholesterol, but not with smoking or alcohol consumption as in the studies by Meade et al. ${ }^{23}$ and Korsan-Bengtsen et al. ${ }^{24}$ The differences in association may relate to selective factors acting upon the populations studied as well as to differences in measurements. Fibrinogen in this study determined some of the variation in plasma viscosity. But plasma viscosity itself was shown to be independently and positively associated with ischaemic heart disease. Plasma viscosity was also positively associated with serum total cholesterol and total triglycerides. Plasma viscosity determined by fibrinogen, other proteins, lipids, and glucose will influence blood viscosity which is determined further by erythrocyte flexibility and mass.

The heparin neutralising activity of platelet poor plasma may be derived from a variety of sources. Heparin neutralising activity is raised after acute myocardial infarction and in the post-infarction state $^{2526}$ and this rise relates, at least in part, to raised fibrinogen levels. When fibrinogen and other heat labile proteins are removed by heating platelet poor plasma, however, the heparin neutralising activity of the plasma remains raised in a proportion of cases of acute myocardial infarction and other thrombotic conditions. ${ }^{27}$ Thus the heparin thrombin clotting time test must be considered as a non-specific measure of the heparin neutralising activity of a number of proteins in platelet poor plasma which have association with ischaemic heart disease.

Antithrombin III was measured in serum and represents residual levels after clotting. The lower levels of antithrombin III observed in subjects with ischaemic heart disease may represent lower preexisting plasma levels contributing to a prothrombotic state or increased usage during in vitro clotting of blood containing higher concentrations of thrombogenic substances.

In considering haemostatic factors in the aetiology of ischaemic heart disease it is realised that there are a large number of such factors which could be measured. Histological studies indicate the involvement of various factors like fibrinogen, fibrin, and platelets. But other work now indicates the importance of endothelial damage, ${ }^{28}$ intraendothelial and intraplatelet prostaglandins, ${ }^{10}$ other clotting factors, ${ }^{21}$ and 
mechanisms that neutralise or lyse thrombotic factors $^{23}$ in the processes of thrombogenesis and atherogenesis. Generating and testing hypotheses with these large numbers of factors and mechanisms in epidemiological studies concerned with the aetiology of ischaemic heart disease will be exhausting of resources and public co-operation. The problem is being tackled by separate studies determining initially associations of ischaemic heart disease and its risk indicators with different factors and by the use of more global, non-specific tests like the heparin thrombin clotting times. ${ }^{18}$

The association of blood levels of the above factors with ischaemic heart disease does not necessarily imply causation, and their interpretation must be viewed with caution in cross-sectional studies in particular when only those subjects surviving ischaemic heart disease and other diseases are available. This study has shown both the feasibility of measuring some haemostatic factors in a random population and interesting associations with ischaemic heart disease and some of the established risk indicators. These factors, and others having associations with cardiovascular deaths in the Northwick Park heart study, ${ }^{21}$ are now being measured in a large random sample of men aged 45 to 59 to determine their associations with the incidence of ischaemic heart disease.

\section{References}

1 Mitchell JRA, Schwartz CJ. Arterial disease. Oxford: Blackwell Scientific Publications, 1965: 178-209.

2 Fulton WFM, Sumner DG. 125I-labelled fibrinogen, autoradiography, and stereoarteriography in identification of coronary thrombotic occlusion in fatal myocardial infarction (abstract). Br Heart $\mathcal{F}$ 1976; 38: 880.

3 Duguid JB. Thrombosis as a factor in the pathogenesis of coronary atherosclerosis. I Pathol Bacteriol 1946; 58: 207-12.

4 Crawford T, Levene CI. The incorporation of fibrin in the aortic intima. F Pathol Bacteriol 1952; 64: 523-8.

5 Woolf $\mathrm{N}$. The distribution of fibrin within the aortic intima. Am F Pathol 1961; 39: 521-32.

6 Carstairs KC. The identification of platelets and platelet antigens in histological sections. F Pathol Bacteriol 1965; 90: 225-31.

7 Smith EB, Staples EM, Dietz HS, Smith RH. Role of endothelium in sequestration of lipoprotein and fibrinogen in aortic lesions, thrombi, and graft pseudointimas. Lancet 1979; ii: 812-6.

8 Jorgensen L, Haeram JW, Chandler AB, Borchgrevink CF. The pathology of acute coronary death. Acta Anaesthesiol Scand 1968; suppl 29: 193-9.

9 Mustard JF. Platelets and thrombosis in acute myocardial infarction. Hospital Practice 1972; 7: 115-28.

10 Moncada S, Vane JR. Unstable metabolites of arachidonic acid and their role in haemostasis and thrombosis. Br Med Bull 1978; 34: 129-35.

11 Ross R, Glomset JA, Kariya B, Harker LA. A platelet dependent serum factor that stimulates the proliferation of smooth muscle cells in vitro. Proc Natl Acad Sci USA 1974; 71: 1207-10.

12 Bainton D, Burns-Cox CJ, Elwood PC, et al. Prevalence of ischaemic heart disease and associations with serum lipoproteins in subjects aged 45 to 64 years: the Speedwell study. Br Heart $\mathcal{F}$ 1982; 47: 483-9.

13 Clauss A. Gerrinnungephysiologische Schnellmethode sur Bestimmung des Fibrinogens. Acta Haematol (Basel) 1957; 17: 237-46.

14 Thorp JM, Horsfall GB, Stone MC. A new red-sensitive micronephelometer. Med Biol Eng 1967; 5: 51-6.

15 Harkness J. The viscosity of human blood plasma; its measurement in health and disease. Biorheology 1971; 8: 171-93.

16 von Kaulla E, von Kaulla KN. Antithrombin III and diseases. Am f Clin Pathol 1967; 48: 69-80.

17 Mancini G, Carbonara AO, Heremans JF. Immunological quantitation of antigens by single radial immunodiffusion. International Fournal of Immunochemistry 1965; 2: 235-54.

18 O'Brien JR, Etherington M, Jamieson S, Lawford P, Sussex J, Lincoln SV. Heparin neutralizing activity test in the diagnosis of acute myocardial infarction. $\mathcal{F}$ Clin Pathol 1975; 28: 975-9.

19 Hampton JW, Mantooth J, Brandt EN, Wolf SG Jr. Plasma fibrinogen patterns in patients with coronary atherosclerosis. Circulation 1966; 34: 1098-101.

20 Pilgeram LO. Relation of plasma fibrinogen concentration changes to human arteriosclerosis. $\mathcal{F}$ Appl Physiol 1961; 16: 660-4.

21 Meade TW, Chakrabarti R, Haines AP, North WRS, Stirling Y, Thompson SG. Haemostatic function and cardiovascular death; early results of a prospective study. Lancet 1980; i: 1050-4.

22 Pilgeram LO. Turnover rate of autologous plasma fibrinogen ${ }^{14} \mathrm{C}$ in subjects with coronary thrombosis. Thrombosis et Diathesis Haemorrhagica 1968; 20: 31-43.

23 Meade TW, Chakrabarti R, Haines AP, North WRS, Stirling Y. Characteristics affecting fibrinolytic activity and plasma fibrinogen concentrations. $\mathrm{Br} \mathrm{Med} \mathcal{F} 1979$; i: 153-6.

24 Korsan-Bengtsen K, Wilhelmsen L, Tibblin G. Blood coagulation and fibrinolysis in a random sample of 788 men 54 years old: 2 . Relations of the variables to "risk factors" for myocardial infarction. Thrombosis et Diathesis Haemorrhagica 1972; 28: 99-108.

25 O'Brien JR. 'Exhausted' platelets continue to circulate (letter). Lancet 1978; ii: 1316-7.

26 O'Brien JR, Etherington MD, Jamieson S, Lawford P, $\widetilde{\Omega}$ Lincoln SV, Alkjaerzig NJ. Blood changes in athero- $N$ sclerosis and long after myocardial infarction and venous thrombosis. Thrombosis et Diathesis Haemorrhagica 1975; 34: 483-97.

27 Okuno T, Crockatt D. Platelet factor 4 activity and $\bullet$ thromboembolic episodes. Am F Clin Pathol 1977; 67: 351-5.

28 Ross R. Atherosclerosis: the role of endothelial injury, smooth muscle proliferation and platelet factors. Triangle 1976; 15: 45-51.

Requests for reprints to Dr I A Baker, Avon Area Health Authority, Greyfriars, Lewin's Mead, Bristol BS1 2EE. 